\title{
BARRIERS BEFORE INNOVATIONS IN FURNITURE COMPANIES
}

\author{
P. Biolcheva* \\ Department Industrial Business, UNWE, Sofia, Bulgaria
}

\begin{abstract}
The dynamics of the environment shows that the competitiveness at the company level is impossible without the presence of innovation activity. Innovation influences consumer opinion, they impose new needs, they refine materials, business processes, technologies and products. Innovation is crucial for the survival, development of Bulgarian industrial companies. Each company's innovation policy is specific, there are no uniform rules or clear instructions for it. It is the basis of creating competitive advantages and it depends on the survival of the company on the market (1). Unfortunately, innovation faces many different barriers. Some of them are of an external nature and are imposed by the environment in which the company operates. Another part is of an internal nature and reflects company culture, management views on development and risk taking, and so on. This paper outlines the state of Bulgarian reality under the conditions of a "timid innovator" and examines the major groups of barriers faced by companies. The work shows an empirical study related to the obstacles to the innovation activity of the Bulgarian managers in the furniture industry.
\end{abstract}

Key words: innovation, innovation barriers, furniture industry

\section{INTRODUCTION}

Bulgarian companies face a number of difficulties in terms of innovation. On the one hand, they relate to our psychology, on the other with motivation, on the third with financial possibilities. All this does not allow them to tate place among the most innovative in the international arena. For 2016 according to the global innovation index, Bulgaria is 38th out of a total of 128 countries. The index classifies countries according to their innovative capabilities based on nearly 80 indicators, including infrastructure, human resources, institutions, market conditions, business conditions, knowledge and technology, creativity. By these criteria, Bulgaria receives 41 points out of a possible 100 (2). These data are a testimony to the fact that Bulgarian companies show their aspirations and efforts in their innovativeness. However, there are a number of barriers to innovation as discussed in this paper. In order to clarify them, it is first necessary to address the innovations themselves and their manifestation.

\footnotetext{
*Correspondence to: Petya Biolcheva, Department Industrial Business, UNWE, Sofiq, Bulgaria, 1700 Sofia, Studentski Grad "Hristo Botev“,e-mail: p.biolcheva@unwe.bg, tel.0887695738
}

\section{Classification of Innovation}

Innovation can be classified by multiple signs. For the purposes of the present work, a short classification concerning the feasibility of the object being surveyed, namely furniture companies, is given.

- According to the object of innovation: technological, product, process, market and organizational-management innovation.

- According to the degree of innovation and investment innovations are: fundamental, improved, pseudo-innovation.

- According to innovation, innovation is classified as: new global products (radical innovations); New to the company; New products complementing existing business products; Sophisticated products; Repackaged products; New products with lower prices.

- Depending on the extent to which innovation is changing consumer behavior, successive innovations are more satisfying to customer needs; Innovations that change the way of meeting certain needs; Innovations that impose new consumer habits.

- According to the reason that led to the creation and implementation of innovations: driven and pushed innovations.

- According to the degree of coercion, innovation is subdivided into forced and elective. (3) 
- There is a need to add another kind of innovation to the classification of innovation, you have a bearing on furniture production, namely eco-innovation. Eco-innovation is any innovation that leads to significant progress towards achieving the goal of sustainable development by reducing the impact of production methods on the environment, increasing the resilience of nature to environmental pressures, or achieving a more efficient and responsible use of natural resources.(4)

Most companies have a portfolio of innovations, including both partial improvements to existing processes, products and organization, and radical innovations. Good corporate management requires their skillful balancing according to specific business needs.

\section{Clasification of Inovation Bariears}

Notwithstanding the advantages (increased competitiveness, cost reduction, market share, etc.) that innovation provides to the company, its realization can not be described as a smooth and seamless process. For various reasons, subjective and objective, the realization of company innovation faces barriers that innovators have to overcome on the road to achieving the goals.

Innovative barriers can be classified as internal and external. External barriers to innovation are a product of external environment factors (general and specific). Innovative barriers to the common external environment include: the political-legal component, socio-cultural features, macroeconomic characteristics, and technologies. Internal barriers are known as corporate barriers to innovation activities. Internal and external barriers are schematized and some of their elements are summarized in Table 1.

Table 1. Internal and external barriers to innovation development

\begin{tabular}{ll}
\hline & Barriers to Innovation \\
\hline Internal barriers & External barriers \\
High costs & Insufficient government support \\
Excessive risk & Economic shocks \\
Difficult control of innovation costs & Lack of marketing information \\
Lack of qualified staff & Lack of regional infrastructure \\
Tough access to financial resources & Lack of information on new technologies \\
Difficult maintenance of highly qualified staff & Lack of opportunities for external partners \\
Lack of internal training for employees & \\
Adaptability of employees at change & \\
\hline
\end{tabular}

The barriers to innovation financing are the most difficult to overcome and most seriously affecting the innovation activity of firms (especially small and medium-sized companies). They are result from:

- serious investment in field of innovation;

- high risk associated with innovation projects;

- difficulties in determining the rate of return on investment made and the amount of expected cash flows;

- the lack of sources for direct financing of innovation projects;

- the too long return on innovation costs.

Another large group is the barriers related to company policy in the field of innovation: most often they stem from the lack of clear priorities for development of the company's innovation activity, insufficiently developed system for stimulating and recognizing the work of innovators, etc. The problems here are related to the lack of good enough conditions for the training, development and work of people involved in innovation; Poorly developed network of contacts at company level, industry, national economy and international achievements; Insufficient and untimely support of the innovation activity by the strategic managers and the owners of the company; Lack of sufficient competence of the company for the respective technological field. Solutions to overcoming these barriers may include providing freedom of action for creative people in companies; Creating strategic alliances with competitors; Mergers with companies that have know-how in the field. The barriers to production require: expansion of the production base; Adaptation of existing production capacities.

- Restricted access of the company to the market: lack of cooperation with the main supplier of the market; Lack of its own distribution system; Lack of any strategy, especially the implementation of a market pull strategy i.e. aggressive supply and sales promotion among end customers who, through 
their search, are stimulating distributors to buy the new product. (5)

- $\quad$ Staff barriers - lack of specialists with appropriate education and professional experience at all stages of the innovation process. Particularly specific are the barrier barriers in the stage of generating ideas. This is an extremely creative process and requires the presence of specialists who, apart from the special professional knowledge in the field, are also trained in the methods of engineering creativity, by which many obstacles are eliminated at the stage of generating ideas.

The staff barriers in the generation of ideas in most cases are related to the underestimation of the functions that a particular subject can perform beyond the standard concepts of its application; Use of certain (same) methods and approaches that are not always appropriate to resolve emerging issues; Incorrect approach to problem solving - too rapid adoption of the first solution without detailed assessment of all possible options, however unreal to appear at first glance; Excessive specialization, which sometimes unjustifiably narrows the horizons and hinders the search for and perception of ideas.(6)

Staff in today's innovative enterprise should be well aware of issues related to market research and marketing of new products, choice of goals, tasks and strategy of the company, organization and management of research, modern information technologies and business communications, which are the basis of the innovative culture.

- Organizational barriers - in the conditions of small and medium-sized enterprises, there can be no talk of creating special organizational forms (structural units) dealing only with the issues of innovation. But the overcoming of organizational barriers can start with specific tasks of handling information coming through different channels to individual specialists regardless of their place in the organizational structure. Similar requirements of employees can be reflected in their job descriptions.

- $\quad$ Psychological barriers - Psychological barriers are different in nature and occur in the initial stages of the innovation process. Such are the fear of criticism or not accepting the ideas proposed; Fear of consumer attitudes; Fear of disapproval by managers. Often specialists fall under the influence of the claims of recognized authorities in an area, which prevents them from developing and adopting ideas that contradict the perceived perceptions. Psychological barriers are especially characteristic of the stage of creating the innovative product. The realization of the innovation idea requires the spending of significant resources, but the expected results are still in the field of probabilities. It is clear that there is a certain risk to their achievement, which is determined both by the company's activity and by the independent conditions of the external environment in which it operates. (7)

- Consumer barriers - these kinds of barriers are seen in "lack of consumer interest in new goods or services". Most of this kind of consumption is dictated by cultural, social, personal and other motives. If the new product or service does not conform to the specifics of the user group, the probability of not realizing is too great. (6)

\section{The Bulgarian reality in a state of "timid innovator"}

As identified in the Innovation Strategy for Intelligent Specialization, Bulgaria falls into the group of countries "timid innovators, whose performance is more than $50 \%$ below the EU-27 average, and holds the last place in innovation performance among EU-27. Comparing the innovative characteristics of Bulgarian SMEs with those of the EU-27 the most significant is the distance of Bulgaria by indicator "collaborations". The main recommendation of the EU Council (8) on innovation and competitiveness concerns precisely the partnerships between universities, research units and industry. Promoting the exchange of ideas, the transfer and commercialization of research results. The Bulgarian economy has not yet entered the transition from an efficient economy to a high level of development ("knowledge-based economy") (9), which puts it in the position of a "catching-up" state. The Operation program innovation and competition 2014-2020 seeks opportunities to accelerate the transition to a knowledge-based economy by encouraging investment in potential thematic areas for intensive innovation development and innovative horizontal policies in line with the Innovation Strategy for Intelligent Specialization.

To move closer to the EU average, Bulgaria should make further efforts for coordinated support, both aimed at increasing efficiency indicators and indicators for a "knowledgebased economy" (high level of development), with innovation being perceived As an indivisible element of competitiveness. According to the Bulgaria Assessment Report for Bulgaria, most of the Bulgarian companies are operating below the technological limit and 
"their growth is based on sources of productivity improvements that are not related to $\mathrm{R} \& \mathrm{D}$ and knowledge dissemination, nor to the generation of Knowledge ".(10) Even the direct foreign investments attracted so far in the economy have limited contributions to the technology transfer. In order to improve its competitiveness, Bulgaria should emphasize both the quality of the workforce and the development of opportunities for adopting and adapting European and international knowledge and technologies. This calls for innovation policy to be geared to specific areas and to combine the promotion of R \& D-based innovation activities with those that are not directly related to $\mathrm{R} \& \mathrm{D}$.

\section{Furniture industry a general characteristic}

In the furniture manufacturing sector $1.6 \%$ of the industrial production volume is produced in the country and $2.1 \%$ of the value added in the industry is also created.

The industry employs 21.9 thousand people (4.2\% of those employed in industry). The salary level in the sector is one of the lowest for the country - the average monthly salary is 700 levs.

The Industrial Production Index and Turnover Index in the sector in 2015 increased by $7.1 \%$ and $3.0 \%$, respectively. The production of the enterprises in the branch amounted to BGN 0.82 billion. In 2015 the turnover of the furniture-producing foreign markets amounted to BGN 408 million. In the domestic market, the sector generated output for BGN 478.8 million. In 2015 A slight increase of $0.2 \%$ was recorded in producer prices compared to the previous year.

Leading activities in the branch include the production of office and shop furniture, kitchen furniture, other furniture, mattresses and mattresses. There are 2741 companies in the sector, $51.2 \%$ of which are located in the territory of Sofia, Plovdiv, Varna, Troyan, Pazardjik and Blagoevgrad. Parallel Ltd., TED BED EAD, Ekon 91 OOD, Sredna Gora AD and others are more prominent in the production of furniture.

In 2015, the furniture industry exports increased by $3.5 \%$. The share of the sector in the export of industrial goods amounts to $1.3 \%$. Leading countries in the export of $\mathrm{C} 31$ are Germany, Italy, France, the Czech Republic and the UK. (11)

\section{Innovations in the furniture industry}

The innovation activity of the furniture companies in Bulgaria is formed by the combination of their innovative activities. In its formation, there are a number of factors such as: size of the enterprise (innovation activity increases with increasing number of employees); Age of machinery and equipment (innovation activity is growing in enterprises with newer machinery and equipment); Education and staff qualification (innovation activity depends on the company culture and the propensity for innovation); Access to finance (innovation activity is increasing by facilitating access to finance), etc.

The furniture companies show their innovative intentions in the following categories:

- Product innovators - they find expression in creating sophisticated furniture, new to the enterprise;

- Process innovators - new production methods;

- Organizational innovators - new methods of work organization;

- Marketing innovators - changes in aesthetic design;

- Eco-innovators - using procedures to reduce the harmful impact of production, including reducing or replacing materials with safer substitutes. (12)

Regarding the innovation of the furniture companies, it can be said that a large part of the Bulgarian factories in the furniture manufacturing sector are competitive on the market because of the still low cost of the final product. However, most of them feel the economic need to invest in innovation as a major way to increase their competitiveness. Their needs are primarily related to innovations that improve the efficiency of internal business processes. Successful innovations bring higher revenue, increased sales or additional added value of products. A great deal of the companies have financial support for investing in such activities

The main barriers to the implementation of such projects are several: a disconnected "science-business" link, a lack of incentives for commercialization of scientific results, a poorly developed technology transfer infrastructure. Bulgarian companies have a low innovative culture. In most cases, they link innovation to new technologies and do not give enough attention to the importance of process innovation. In foreign-owned enterprises, there is some dynamics in the implementation of innovation. (13)

\section{Empirical research}

In order to identify the practical barriers posed by the Bulgarian companies in terms of their innovation activity, an empirical study was 
also carried out. Its scope includes 15 mediumsized industrial companies, including Sredna Gora AD, Hamefa AD, Hit Design AD, Acrypol Coatings LTD and others. The survey consists of a questionnaire filled in by the managers of the surveyed companies. The questions whose response is sought by the respondents are mostly closed, with guiding answers and related to different types of barriers to the introduction of innovations. Different statistical methods and means of data processing were used. The empirical study aims to obtain reliable information about the study, on the basis of which the necessary analyzes, conclusions and summaries can be made.

\section{Survey results}

All interviewed respondents find it necessary to invest in innovation in their managed companies. Due to the dynamic nature of the business environment, this has to be done on a permanent basis, with about $70 \%$ of them introducing different partial innovations each year. Less than $10 \%$ bring innovations every 5 years. The introduced innovations depend on the specific needs of the companies, but in their generalized version it can be said that the managers of furniture companies in Bulgaria invest mainly in technological innovations (about $50 \%$ ), followed by product (33\% Less in organizational and management innovation (less than 20\%).

To sustain sustainable development over the long term, respondents surveyed assess the scale of the 1 to 5 scale (where 5 is the highest rating) on the scale of the future innovation needs. The results show that the need for innovation is in the near range, but the dominant needs are mostly product and technological innovation. (Figure 1)

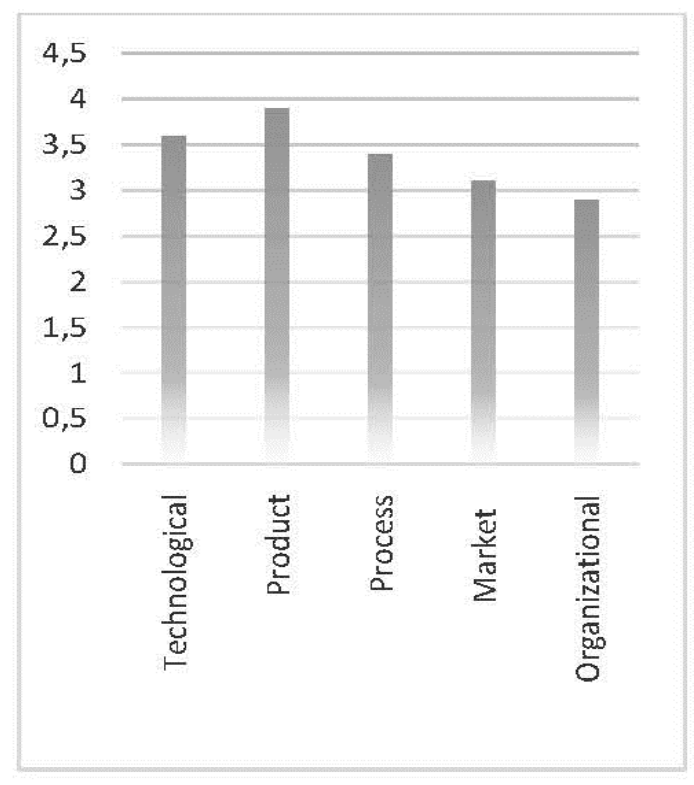

Figure 1. Necessity of innovation to sustain the sustainable development of furniture companies

All of the companies surveyed have Most often these are barriers related to encountered barriers to introducing innovation. infrastructure and behavioral problems.

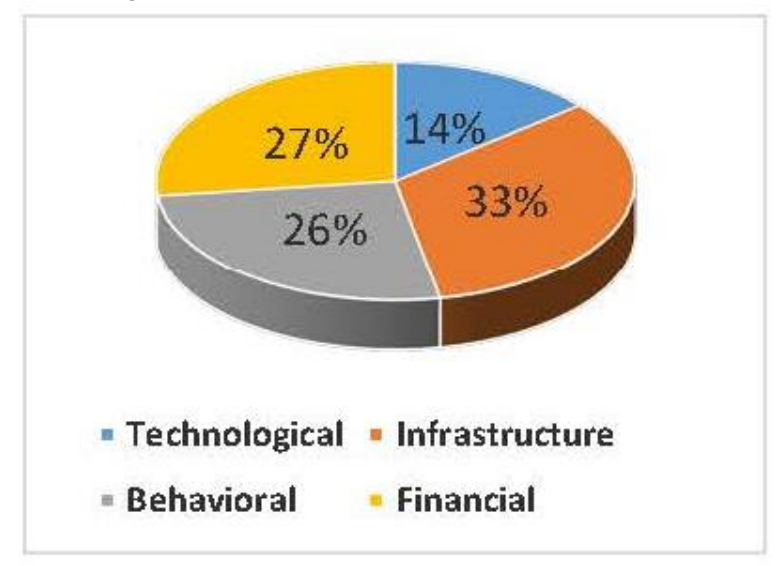

Figure 2. Types of barriers related to the introduction of innovations in the furniture companies in Bulgaria 
Another problem that stands out as a barrier faces legislative or regulatory barriers to introducing innovation in industrial firms. Over $45 \%$ of companies have encountered such problems.

In recent years, a large part of the innovations of the industrial companies in Bulgaria have been carried out with the help of various European programs. About $70 \%$ of surveyed companies have taken advantage of this opportunity. The most preferred programs are: Operational Program "Innovation and Competitiveness", "Regions in Growth", "Development of Human Resources" and others. Some industrial firms (around 35\%) have experienced difficulties in working with the operational programs. The main problems that the respondents diverge are:

- delays in the annual indicative programs;

- the possibility for the beneficiaries to ask questions in preparation for the application is often meaningless due to the fact that: the answers are delayed by 30-40 days, they are published in huge documents on the websites of the programs, and in a given question very often the answer is a reference to another similar a question that is a reference to a third, etc.

- project managers' manuals are delayed;
- information project evaluation issues;

- problems with delay in payments on projects;

One of the main barriers to the introduction of corporate innovations is related to their financing. Nearly $70 \%$ of the surveyed companies responded to such difficulties. In part of them, the funding is related to the provision of external sources and as a result they have experienced difficulties. In $46 \%$ of firms, these difficulties are related to the long period of return on innovation costs. The study shows that the average return on investment in innovation in Bulgarian furniture companies is 3 years, and it is only technological partial innovation. Unfortunately $27 \%$ of companies are suffirg financial due to unsuccessful innovations. This is mainly due to the fact that a large number of companies do not have a fully developed innovation policy, nor do they train employees to create innovative thinking.

Another important aspect for introducing successful innovations is related to the origin of ideas for innovation in companies. The results show that more than half of the companies rely on external sources for innovation. (Figure 3) Most of the companies surveyed do not find it necessary to search for innovative solutions themselves and do not seek specialists in this field.

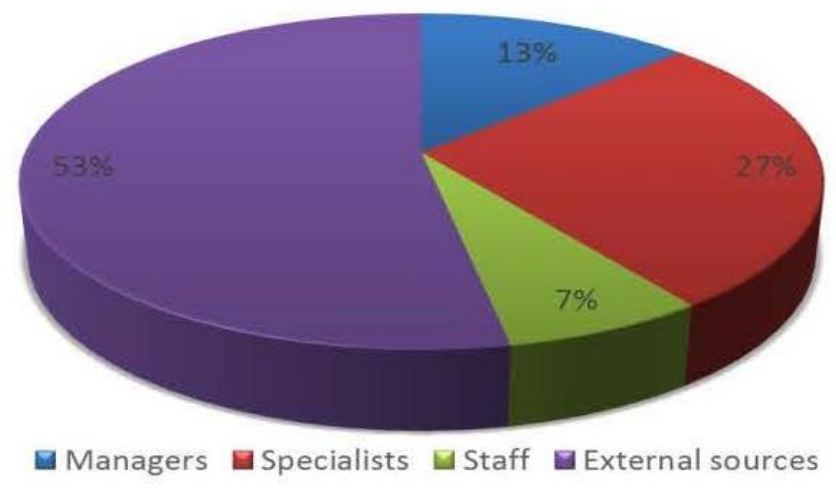

Figure 3. Sources of Ideas for Innovation

Other barriers that furniture managers are struggling with are limited access to a market; Problems with major suppliers; Psychological barriers to generating innovative solutions; Finding good specialists, etc.

Innovative proprietary distribution systems contribute to the development of innovation; The participation of companies in various branch organizations from which they draw ideas for innovation, the availability of specialized industrial exhibitions, the Internet and others.

\section{CONCLUSION}

Barriers to innovation are a broad, diverse group that imposes a number of constraints in pursuing sustainable growth at company level. Overcoming innovative barriers requires considerable effort, including the creation of an integrated set of interrelated actions between different business units. It is necessary to create a company culture in terms of generating innovative solutions that create specific competitive advantages. This will facilitate the process of innovation development, and from there it will also help 
to create prerequisites for sustainable development of companies in the long run.

\section{REFERENCES}

1. Oukes, T., Innovating work behavior, University of Twente, pp.15, 2010

2. Bulgaria mina stapka napred $\mathrm{v}$ klasatsia po inovativnost, vk. Dnevnik, 16,08,2016

3. Georgiev, I., Tsvetkov, Ts., Blagoev, D., Menidzhmant na firmenite inovatsii i investitsii, UNSS, str.112-117, 2013

4. Ecoinovatsii - kliuch kam badeshta konkurentosposobnost na Evropa, Evropeiska komisiq, http://ec.europa.eu/environment/pubs/pdf/fa ctsheets/ecoinnovation/bg.pdf

5. Problemi na inovatsionnite deynosti $\mathrm{v}$ Republika Bulgaria i Evropa, http://drugi.dokumentite.com/art/problemina-inovacionnite-deinosti-v-republikabylgariq-i-evropa/84363

6. Vanev, B., Kolektiv, Inovatsiite politika i praktika, fondatsia za prilozhni izsledvania ARC FUND, 2004, s.432-437; 445-446

7. http://ikonomika.dokumentite.com/art/indus trialen-menidjmynt/65/p76
BIOLCHEVA P.

8. Preporaki na saveta ot 9 yuli 2013 godina otnosno Natsionalnata programa za reformi na Bulgaria za 2013 g. i stanovishte na Saveta otnosno Konvergentnata programa na Bulgaria za perioda 2012-2016

9. http://www3.weforum.org/docs/WEF_Glob alCompetitivenessReport_2013-14.pdf

10. Radoshevich, S., Strogilopulus, G., Strategii za intelegentna spetsializatsiq $\mathrm{v}$ oblasta na nauchnite izsledvaniq I inovaciite. Otsenka na Bulgariq. Evropeiska komisiq, 2012

11.Ministerstvo na ikonomikata, https://www.mi.government.bg/bg/themes/ manufacture of-furniture- 31-530-276.html

12.Ivanova, D., Popova, R., Pokazateli za izmervane na inovatsionnata aktivnost na mebelnite predpriyatia, Yundola, 2012

13. Natsionalen doklad za darvoobrabotvashtata i mebelnata promishlenost $\mathrm{v}$ R. Bulgaria, PROJECT INNO Trans, $2015 \mathrm{O}$ Trans, 2015 